\title{
ALEITAMENTO MATERNO E SEUS BENEFÍCIOS: PRIMEIRO PASSO PARA A PROMOÇÃO SAÚDE
}

\section{Editorial}

O aleitamento materno é reconhecido pelo Ministério da Saúde, em consonância com a Organização Mundial de Saúde (OMS) e Fundo das Nações Unidas para a Infância (UNICEF), como uma das estratégias fundamentais para a diminuição dos índices de mortalidade neonatal ${ }^{(1)}$. É pacífico o fato de que o aleitamento materno deva ser iniciado após o parto, uma vez que o colostro é considerado a primeira imunização do neonato pela presença de imunoglobulinas e maior quantidade de proteínas e vitamina $\mathrm{A}^{(2)}$.

Recomenda-se o aleitamento materno exclusivo até o sexto mês de vida, podendo ser dado como suplemento alimentar até os dois anos de idade ou mais ${ }^{(3,4)}$. Então, é papel do profissional de saúde, em qualquer área de atuação, incentivar, estimular e apoiar o aleitamento materno ${ }^{(5)}$.

Dentre as ações de promoção, proteção e apoio ao aleitamento materno do Ministério da Saúde implementadas nos últimos 30 anos destacam-se a Iniciativa Hospital Amiga da Criança (IHAC), que prioriza os 10 passos para o aleitamento materno, a criação da Norma Brasileira de Comercialização de Alimentos para Lactentes (NBCAL), a Rede Brasileira de Bancos de Leite Humano (REDEBLH), as campanhas anuais como Semana Mundial da Amamentação (SMAM) e Dia Nacional de Doação de Leite Humano, e, mais recentemente, a Rede Amamenta Brasil $^{(6)}$

Observam-se os inúmeros benefícios do aleitamento materno relacionados aos aspectos nutricionais e emocionais, em que esse aleitamento aparece como fonte de nutrientes, em quantidade e qualidade adequadas ao bebê, sendo ao mesmo tempo promotor da relação mãe-filho ${ }^{(5)}$. A interação mãe-filho durante a amamentação favorece o desenvolvimento dos laços afetivos para a aprendizagem mútua, visto que gera afeto, segurança, acolhimento e contribui para o desenvolvimento da linguagem e a construção da inteligência. A mãe aprende sobre o comportamento do bebê e sobre seu papel de mãe; o bebê aprende a se relacionar com sua mãe e com o mundo através dela.

Além disso, o ato de amamentar promove o desenvolvimento facial infantil, contribuindo positivamente para a mastigação, deglutição, respiração e articulação dos fonemas, no que tange aos aspectos relacionados ao desenvolvimento sensóriomotor oral, especificamente no que se refere à posição, pega, força de sucção e coordenação entre as funções de sucção, deglutição e respiração(7).

$\mathrm{O}$ aleitamento materno pode ser determinado por inúmeros fatores que abrangem desde aspectos individuais, relativos aos neonatos e as suas mães e famílias; até determinantes contextuais como a realidade socioeconômica, a capacitação dos profissionais de saúde, a atuação de serviços e políticas públicas. E que, apesar de biologicamente determinada e culturalmente condicionada, a amamentação constitui-se em um processo complexo impregnado de ideologias e valores culturais ${ }^{(8)}$.

Apesar dos inúmeros benefícios do aleitamento materno, constata-se que em algumas situações pode haver indicação para complementar ou até mesmo para não oferecê-lo. O Ministério da Saúde ${ }^{(9)}$ publicou, em edição revisada e ampliada, as 
razões justificadas para o uso de substitutos do leite materno. Dentre as contraindicações para o aleitamento materno estão as doenças metabólicas que podem afetar o lactente, como a galactosemia, a fenilcetonúria e a doença do xarope de bordo, bem como os casos de mãe HIV-positiva. Além disto, o uso de medicamentos, como os antimetabólitos, iodo radioativo, xanax, anticoncepcional oral com estrogênio, parlodel, cloromicetina, valium, ergotamina, norplant e pedofilina, também são contraindicados ${ }^{(9)}$.

Vale ressaltar que a maioria dos medicamentos utilizados por mulheres durante este período é compatível com a amamentação. Entretanto, pela falta de conhecimento de muitos profissionais da saúde, a lactação acaba sendo interrompida ${ }^{(6)}$.

Nesta edição, a RBPS traz a temática aleitamento materno, discutindo essa prática mesmo com a lactante em uso de medicação, reforçando a importância da continuidade do aleitamento como uma ação de promoção da saúde do recém-nascido. Nesse ínterim, se destaca que crianças amamentadas ao peito parecem apresentar menores chances de obesidade, culminando com adultos mais saudáveis.

\section{REFERÊNCIAS}

1. Bezerra VLVA, Nisiyama AL, Jorge AL, Cardoso RM, Silva EF, Tristão RM. Aleitamento materno exclusivo e fatores associados a sua interrupção precoce: estudo comparativo entre 1999 e 2008. Rev Paul Pediatr. 2012;30(2):173-79.

2. Oddy WH. Breastfeeding in the first hour of life protects against neonatal mortality. J Pediatr. 2013;89(2):10911.
3. Ministério da Saúde (BR), Secretaria de Políticas da Saúde. Área Técnica da Criança. Atenção humanizada ao recém-nascido de baixo peso - Método Canguru: manual do curso. Brasília: Ministério da Saúde; 2011.

4. Pérez-Escamilla R, Vianna RPT. Breastfeeding and infant pneumonia in Brazil: the value of electronic surveillance information systems. $\mathrm{J}$ Pediatr. 2011;87(5):371-2.

5. Silva WF, Guedes ZCF. Time of exclusive breastfeeding of preterm and term newborn babies. Rev CEFAC. 2013;15(1):160-71.

6. Ministério da Saúde (BR), Secretaria da Atenção à Saúde, Departamento de Ações Programáticas e Estratégicas. Amamentação e uso de medicamentos e outras substâncias. $2^{\mathrm{a}}$ ed. Brasília : Ministério da Saúde; 2010.

7. Silveira LM, Prade LS, Ruedell AM, Haeffner LSB, Weinmann, ARM. Influence of breastfeeding on children's oral skills. Rev Saúde Pública. 2013;47(1):37-43.

8. Sanches MTC. Amamentação: enfoque fonoaudiológico. In: Carvalho MR,Tavares LAM. Amamentação bases científicas para a prática profissional. $3^{\text {a }}$ ed. Rio de Janeiro: Guanabara Koogan; 2010. p. 101-22.

9. Organização Mundial da Saúde - OMS, Fundo das Nações Unidas para a Infância, Ministério da Saúde. Iniciativa Hospital Amigo da Criança. Edição revisada, atualizada e ampliada para o cuidado integrado. Brasília; 2009. (Módulo 4, Anexo D. Normas e Manuais Tecnicos). 